А. А. Прищепов

Белорусский государственный технологический университет

\title{
СРАВНИТЕЛЬНЫЙ АНАЛИЗ ПОКАЗАТЕЛЕЙ ЛИНЕЙНОГО ПРИРОСТА ПОДРОСТА СОСНЫ ДО И ПОСЛЕ ПРОВЕДЕНИЯ РУБКИ ОБНОВЛЕНИЯ
}

\begin{abstract}
Для проведения исследований были заложены три пробные площади на территории лесного фонда Нарочанского лесничества ГОЛХУ «Вилейский опытный лесхоз» в выделах с одинаковыми условиями произрастания (сосняк мшистый), где был проведен первый прием рубок обновления и присутствует подрост сосны обыкновенной предварительной генерации. Одна пробная площадь (контрольная) заложена в выделе с аналогичными условиями произрастания, где рубка обновления не проводилась. На каждой пробной площади были подобраны модельные особи подроста сосны предварительной генерации, у которых проводилось измерение годичных приростов в высоту за весь период жизни. Полученные данные были подвержены статистическому анализу с применением $t$-критерия Стьюдента для установления достоверности различий между значениями прироста соснового подроста.

В результате исследований было установлено, что в период жизни соснового подроста до проведения рубки обновления различия в показателях линейного прироста на экспериментальных и контрольной пробных площадях статистически не различимы. В период жизни после проведения рубки обновления значения линейного прироста на пробных площадях в среднем на 44,3\% выше, чем на контрольной пробной площади. Также установлено, что проведение первого приема рубки обновления поспособствовало увеличению среднегодичного линейного прироста подроста сосны обыкновенной на $33,5 \%$.
\end{abstract}

Ключевые слова: рубка обновления, сосна обыкновенная, линейный прирост.

Для цитирования: Прищепов А. А. Сравнительный анализ показателей линейного прироста подроста сосны до и после проведения рубки обновления // Труды БГТУ. Сер. 1, Лесное хоз-во, природопользование и перераб. возобновляемых ресурсов. 2021. № 1 (240). С. 13-19.

\section{A. A. Prishchepov \\ Belarusian State Technological University}

\section{COMPARATIVE ANALYSIS OF INDICATORS OF LINEAR GROWTH OF PINE UNDERGROWTH BEFORE AND AFTER THE REGENERATION FELLING}

To carrying out of research three trial plots were laid on the territory of the forest fund of the Vileika Experimental Forestry in the areas with the same growing conditions (Pinetum pleuroziosum), where the first reception of regeneration felling was carried out and there is an pine undergrowth preliminary generation. One trial plot (control) was laid in an area with similar growing conditions, where regeneration felling was not carried out. On each trial plot, model specimens of pine undergrowth of preliminary generation were selected, in which the annual height growths were measured for the entire life period. The data obtained were subjected to statistical analysis using the Student's t-test to establish the reliability of differences between the values of the growth of pine undergrowth.

As a result of the research, it was found that during the life of pine undergrowth before the regeneration felling, the differences in linear growth rates on the experimental and control trial plots are not statistically distinguishable. During the period of life after the regeneration felling, the values of linear growth on the trial plots are on average $44.3 \%$ higher than on the control trial plot. It was also found that the first reception of regeneration felling contributed to an increase in the average annual linear growth of pine undergrowth by $33.5 \%$.

Key words: regeneration felling, Pinus sylvestris L., linear growth.

For citation: Prishchepov A. A. Comparative analysis of indicators of linear growth of pine undergrowth before and after the regeneration felling. Proceedings of BSTU, issue 1, Forestry. Nature Management. Processing of Renewable Resources, 2021, no. 1 (240), pp. 13-19 (In Russian).

Введение. Текущий прирост деревьев является объективным показателем, который характеризует их рост и состояние, а также синтезирует результаты жизнедеятельности растительного организма. Особое значение имеет этот показатель для оценки состояния подроста, так как древостой может оказывать на его формирование как отрицательное, так и положительное воздействие [1]. 
Прирост деревьев в сосняках является важнейшим таксационным показателем как отдельно стоящего дерева, так и всего древостоя. $\mathrm{C}$ помощью прироста можно оценить потенциальную продуктивность древостоя, добротность условий местопроизрастания, конкурентные взаимоотношения между компонентами насаждений [2].

Значительное влияние на прирост деревьев могут оказывать внешние факторы среды. Изменение прироста в пределах одного участка леса может различаться по всем годам либо иметь сходство в отдельные годы. Это может быть связано с особенностями климатических условий в различные годы [1].

В условиях ограниченности ресурсов линейный и радиальный приросты сосны вступают в конкурентные отношения за накопленные деревом запасы питательных веществ. При этом линейный прирост играет роль доминанта по отношению к радиальному, пользуясь преимуществом в использовании запаса ресурсов. Данный механизм, носящий адаптивный характер, обусловливает продвижение кроны в доминирующий ярус даже в ущерб механической прочности ствола, обеспечивая дереву необходимый уровень инсоляции [3].

На величину прироста соснового подроста в высоту также влияет возрастной этап дерева. В возрасте самосева сосна обыкновенная имеет неразвитую корневую систему и небольшую фотосинтезирующую поверхность. По мере разрастания корней и увеличения поверхности хвои ассимилирующая способность растений становится больше, приводя к сравнительно быстрому приросту древесины [4].

Исследованиями было установлено, что прирост дерева по диаметру и высоте достаточно интенсивен в период с 10 до 30 лет, а после постепенно начинает убывать [5].

Наибольшая изменчивость прироста наблюдается в сосняках возраста прореживаний, уменьшаясь в возрасте проходных рубок. Это можно объяснить тем, что в возрасте прореживаний происходит наибольшая дифференциация деревьев как по высоте, так и по энергии роста. Поэтому данный этап развития характеризуется быстрым ростом деревьев в высоту $[6,7]$.

В некоторых исследованиях минимальный прирост подроста наблюдался в возрасте 4 лет, максимальный - в 10 лет. На открытом месте интенсивность роста тем больше, чем крупнее подрост. Под пологом рост идет более равномерно и не прослеживается строгая, как на открытом месте, закономерность, так как на прирост в высоту под пологом леса большое влияние оказывают лимитирующие факторы (свет, биогенные вещества, пожары и т. д.) [8, 9].
В возрасте молодняка влияние полноты на прирост по высоте прослеживается достаточно четко: где наименьшая полнота - прирост максимален, с наибольшей полнотой - минимален [1].

Почвенный фактор не оказывает существенного воздействия на изменчивость линейного прироста сосны. Геоморфология рельефа также не является основополагающим фактором, влияющим на изменчивость прироста [10].

Плохой рост подроста сосны под пологом взрослых древостоев обусловлен не только недостатком света, но и тем, что деревья материнского древостоя своими мощными и хорошо развитыми корнями перехватывают питательные вещества и влагу из почвы [8].

Снятие верхнего гумусового горизонта положительно влияет на появление самосева, однако отрицательно сказывается на дальнейшем формировании подроста, в то время как его перемешивание с минеральной частью почвы благоприятно воздействует как на появление самосева хозяйственно ценных пород, так и на его дальнейший рост и развитие. Поэтому годичный прирост по высоте оказывается больше у тех экземпляров подроста, которые формируются на межбороздном пространстве после проведения там минерализации почвы культиватором КЛБ-1,7 в агрегате с трактором МТ3-82, в отличие от соснового подроста, растущего по дну борозды на обнаженной почве после проведения ее минерализации плугом ПКЛ-70. Разница в годичном приросте между вариантами достигает более 20 см [11].

Немаловажную роль на прирост деревьев в высоту играет генетический фактор. Формирование изменчивости годичного прироста в высоту в пределах отдельных местообитаний может определяться в первую очередь генетическими факторами, обусловливающими диапазон развития признака $[12,13]$.

После проведения рубок ухода в течение первых нескольких лет прирост сосны уменьшается по сравнению с деревьями таких же размеров до рубки ухода, что, возможно, связано с приспособлением к новым условиям, а впоследствии с накоплением ресурсов. Восстановление текущего прироста в высоту до уровня «до рубки» в чистых сосновых насаждениях мшистых происходит в течение $3-5$ лет в зависимости от погодных условий $[14,15]$.

Основная часть. Для проведения исследований были подобраны выделы на территории лесного фонда Нарочанского лесничества ГОЛХУ «Вилейский опытный лесхоз» с одинаковыми условиями произрастания (тип леса - сосняк мшистый, эдафотоп - $\mathrm{A}_{2}$ ), в которых рубка обновления проводилась в один и тот же год. Обязательным условием являлось наличие подроста сосны обыкновенной предварительной генерации (сформированного до момента проведения рубки). 
Таблица 1

Значения линейного прироста подроста сосны обыкновенной до проведения рубки обновления

\begin{tabular}{|c|c|c|c|c|c|c|c|c|c|}
\hline \multirow[b]{2}{*}{$\begin{array}{c}\text { Номер } \\
\text { ПIП }\end{array}$} & \multirow[b]{2}{*}{$\begin{array}{c}\text { Средний } \\
\text { возраст, } \\
\text { лет }\end{array}$} & \multirow[b]{2}{*}{$\begin{array}{c}\text { Средняя } \\
\text { высота, } \\
\text { см }\end{array}$} & \multicolumn{5}{|c|}{ Средний линейный прирост по годам, см } & \multirow{2}{*}{$\begin{array}{c}\text { Средний } \\
\text { линейный } \\
\text { прирост } \\
\text { за период, } \\
\text { см }\end{array}$} & \multirow[b]{2}{*}{$\begin{array}{c}\text { Сравнение } \\
\text { с контролем, } \\
\%\end{array}$} \\
\hline & & & 2009 & 2010 & 2011 & 2012 & 2013 & & \\
\hline 1 & 15,3 & 246,1 & $10,4 \pm 3,25$ & $13,9 \pm 5,32$ & $16,3 \pm 4,85$ & $15,8 \pm 4,04$ & $15,8 \pm 4,51$ & $14,4 \pm 4,39$ & $+6,9$ \\
\hline 2 & 14,8 & 237,4 & $10,4 \pm 3,44$ & $15,6 \pm 6,13$ & $17,7 \pm 5,27$ & $16,7 \pm 4,33$ & $16,1 \pm 3,28$ & $15,3 \pm 4,49$ & $+12,4$ \\
\hline 3 & 15,6 & 246,7 & $10,6 \pm 3,52$ & $14,6 \pm 5,75$ & $16,9 \pm 5,30$ & $15,7 \pm 4,37$ & $15,7 \pm 2,74$ & $14,7 \pm 4,33$ & $+8,8$ \\
\hline $1 \kappa$ & 15,1 & 163,2 & $11,5 \pm 3,25$ & $14,0 \pm 5,32$ & $11,5 \pm 1,82$ & $12,5 \pm 3,85$ & $17,5 \pm 5,16$ & $13,4 \pm 3,88$ & - \\
\hline
\end{tabular}

Всего было заложено четыре пробные площади (ПП). В трех из них в 2013 г. был проведен первый прием рубки обновления. Четвертая пробная площадь является контрольной.

Пробная площадь № 1 заложена в 83-м квартале 3-м выделе, интенсивность рубки - 18\%.

Пробная площадь № 2 заложена в 103-м квартале 8-м выделе, интенсивность рубки - 21\%.

Пробная площадь № 3 заложена в 103-м квартале 17-м выделе, интенсивность рубки - 17\%.

Контрольная пробная площадь № 1к заложена в 82-м квартале 12-м выделе. Рубка обновления здесь не проводилась.

На каждой пробной площади были подобраны 20 модельных особей подроста сосны, у которых с помощью мерной рулетки измерялись общая высота и ежегодный линейный прирост. Возраст определялся глазомерно путем подсчета количества мутовок.

Результаты измерений были разделены на два массива данных: «до проведения рубки обновления» (с 2009 по 2013 г.) и «после проведения рубки обновления» (период с 2014 по 2020 г.). Полученные значения обрабатывались в Microsoft Excel с применением режима «Описательная статистика», позволяющего сгенерировать одномерный статистический отчет по основным показателям: среднее значение прироста в высоту за каждый год, стандартное отклонение от среднего значения величины прироста и средний линейный прирост за весь рассматриваемый период [16].
Результаты описательной статистики данных измерений линейного прироста на пробных площадях до проведения рубки обновления представлены в табл. 1.

Как показано в табл. 1, до проведения рубки обновления средние значения линейного прироста на экспериментальных и контрольной пробных площадях практически не отличаются. Максимальное превышение над контролем наблюдается на ПП 2 и составляет $12,4 \%$.

Результаты описательной статистики данных измерений линейного прироста на пробных площадях после проведения рубки обновления представлены в табл. 2.

Проанализировав показатели табл. 2, можно заметить, что значения линейного прироста соснового подроста на пробных площадях с проведенным первым приемом рубки обновления значительно (до 45,4\%) превышают показатели линейного прироста на контрольной пробной площади.

Для дальнейшего сравнительного анализа привели значения линейного прироста по трем пробным площадям к общим средним значениям, чтобы сравнить их с показателями линейного прироста на контрольной пробной площади, а также установить, являются ли наблюдаемые различия в значениях линейных приростов в период после проведения первого приема рубки обновления статистически достоверными.

Таблица 2

Значения линейного прироста подроста сосны обыкновенной после проведения рубки обновления

\begin{tabular}{|c|c|c|c|c|c|c|c|c|c|c|c|}
\hline \multirow[b]{2}{*}{$\begin{array}{c}\text { Номер } \\
\text { ПП }\end{array}$} & \multirow[b]{2}{*}{$\begin{array}{l}\text { Средний } \\
\text { возраст, } \\
\text { лет }\end{array}$} & \multirow[b]{2}{*}{$\begin{array}{c}\text { Средняя } \\
\text { высота, } \\
\text { см }\end{array}$} & \multicolumn{7}{|c|}{ Средний линейный прирост по годам, см } & \multirow{2}{*}{\begin{tabular}{|c|} 
Средний \\
линейный \\
прирост \\
за период, \\
см
\end{tabular}} & \multirow[b]{2}{*}{$\begin{array}{c}\text { Сравнение } \\
\text { с контролем, } \\
\%\end{array}$} \\
\hline & & & 2014 & 2015 & 2016 & 2017 & 8 & 9 & 2020 & & \\
\hline 1 & & 246,1 & $18,1 \pm 4,06$ & $21,8 \pm 5,39$ & $17,2 \pm 6,03$ & $18,7 \pm 6,82$ & $19,8 \pm 6,50$ & $27,5 \pm 6,69$ & $35,2 \pm 5,35$ & $22,6 \pm 5,84$ & \\
\hline 2 & 0 & 237,4 & $17,1 \pm 4,17$ & $22,3 \pm 5,51$ & $16,0 \pm 6,22$ & $17,7 \pm 6,38$ & $17,6 \pm 6,78$ & $25,5 \pm 7,52$ & $34,2 \pm 7,17$ & $21,5 \pm 6,25$ & $+42,3$ \\
\hline 3 & & 246,7 & $16,6 \pm 3,53$ & $22,1 \pm 5,03$ & $17,4 \pm 5,68$ & $19,6 \pm 6,83$ & $19,3 \pm 5,94$ & $27,9 \pm 7,28$ & $35,8 \pm 6,84$ & $22,7 \pm 5,88$ & $+45,4$ \\
\hline $1 \kappa$ & 15,1 & 163,2 & $11,0 \pm 2,47$ & $11,5 \pm 3,10$ & $12,0 \pm 1,32$ & $10,0 \pm 1,26$ & $15,0 \pm 3,80$ & $13,5 \pm 1,64$ & $13,9 \pm 1,57$ & $12,4 \pm 2,16$ & - \\
\hline
\end{tabular}


Сводная таблица средних значений годичного линейного прироста на пробных площадях

\begin{tabular}{|c|c|c|c|c|c|c|c|c|c|c|c|c|}
\hline \multirow{3}{*}{ Номер ПП } & \multicolumn{12}{|c|}{ Линейный прирост по годам, см } \\
\hline & \multicolumn{5}{|c|}{ до проведения рубки обновления } & \multicolumn{7}{|c|}{ после проведения рубки обновления } \\
\hline & 2009 & 2010 & 2011 & 2012 & 2013 & 2014 & 2015 & 2016 & 2017 & 2018 & 2019 & 2020 \\
\hline ПП 1 & 10,4 & 13,9 & 16,3 & 15,8 & 15,8 & 18,1 & 21,8 & 17,2 & 18,7 & 19,8 & 27,5 & 35,2 \\
\hline ПП 2 & 10,4 & 15,6 & 17,7 & 16,7 & 16,1 & 17,1 & 22,3 & 16,0 & 17,7 & 17,6 & 25,5 & 34,2 \\
\hline ПП 3 & 10,6 & 14,6 & 16,9 & 15,7 & 15,7 & 16,6 & 22,1 & 17,4 & 19,6 & 19,3 & 27,9 & 35,8 \\
\hline ППс (среднее) & 10,5 & 14,7 & 17,0 & 16,1 & 15,9 & 17,3 & 22,1 & 16,9 & 18,7 & 18,9 & 27,0 & 35,1 \\
\hline ПП 1к (контроль) & 11,5 & 14,0 & 11,5 & 12,5 & 17,5 & 11,0 & 11,5 & 12,0 & $\mathbf{1 0 , 0}$ & 15,0 & 13,5 & 13,9 \\
\hline
\end{tabular}

Данные средних значений годичного линейного прироста на пробных площадях представлены в табл. 3.

Используя средние значения годичного линейного прироста по трем пробным площадям (ППс) и значения линейного прироста на контрольной пробной площади (ПП 1к) из табл. 3 был построен график изменения линейного прироста подроста сосны на пробных площадях по годам. Этот график представлен на рисунке.

Данный рисунок позволяет увидеть, как с течением времени после проведения рубки обновления (2013 г.) величина годичного линейного прироста постепенно увеличивается в отличие от контрольной пробной площади, где показатели прироста остались примерно на том же уровне, что и в период 2009-2013 гг.
Чтобы установить, являются ли наблюдаемые различия между значениями прироста на пробных площадях с проведенной рубкой обновления и значениями прироста на контрольной пробной площади статистически значимыми, данные подверглись статистическому анализу с помощью пакета «Анализ данных» в Microsoft Excel [16].

Так как сравниваемые показатели прироста исследуются в пределах одного периода времени, но на разных участках, то анализируемые выборки в данном случае являлись независимыми. Поэтому для анализа использовался двухвыборочный $t$-критерий Стьюдента с различными дисперсиями [17].

Результаты статистического анализа данных по периодам представлены в табл. 4.

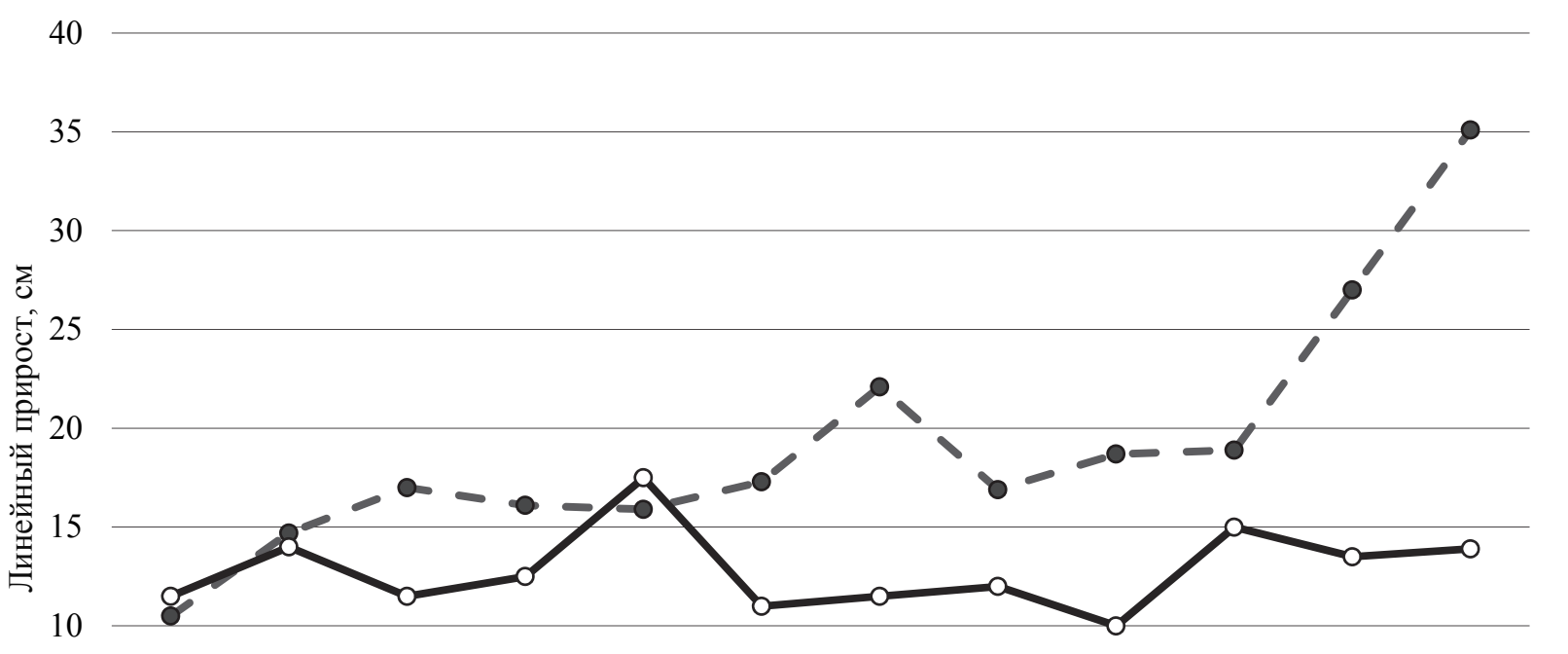

5

0

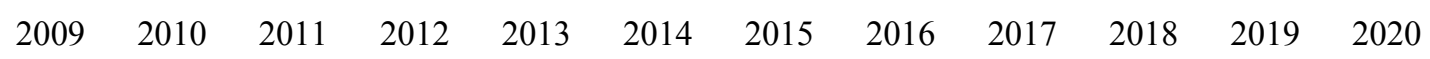
Год

- о- ППс (рубка обновления проведена) — — —П 1к (рубка обновления не проводилась) Динамика линейного прироста подроста сосны по годам на пробных площадях 
Результаты статистического анализа данных по периодам в Microsoft Excel

\begin{tabular}{|c|c|c|c|c|}
\hline \multirow{3}{*}{ Статистический показатель } & \multicolumn{4}{|c|}{ Период } \\
\hline & \multicolumn{2}{|c|}{ 2009-2013 гг. } & \multicolumn{2}{|c|}{ 2014-2020 гг. } \\
\hline & ППс & ПП 1к & ППс & $\Pi \Pi 1 \kappa$ \\
\hline Среднее & 14,79 & 13,35 & 22,24 & 12,38 \\
\hline Дисперсия & 6,56 & 6,30 & 44,11 & 3,09 \\
\hline Наблюдения & 5 & 5 & 7 & 7 \\
\hline Гипотетическая разность средних & \multicolumn{2}{|c|}{0} & \multicolumn{2}{|c|}{0} \\
\hline $\mathrm{d} f$ & \multicolumn{2}{|c|}{8} & \multicolumn{2}{|c|}{7} \\
\hline$t$-Статистика & \multicolumn{2}{|c|}{0,89797} & \multicolumn{2}{|c|}{3,79617} \\
\hline$P(T \leq t)$ одностороннее & \multicolumn{2}{|c|}{0,19771} & \multicolumn{2}{|c|}{0,00337} \\
\hline$t$ критическое одностороннее & \multicolumn{2}{|c|}{1,85955} & \multicolumn{2}{|c|}{1,89458} \\
\hline$P(T \leq t)$ двухстороннее & \multicolumn{2}{|c|}{0,39542} & \multicolumn{2}{|c|}{0,00675} \\
\hline$t$ критическое двухстороннее & \multicolumn{2}{|c|}{2,30600} & \multicolumn{2}{|c|}{2,36462} \\
\hline
\end{tabular}

В табл. 4 отражено, что в период 2009-2013 гг. (до проведения рубки обновления) значение показателя «t-статистика» составляет 0,898 , что меньше значения $t$ критического как одностороннего $(1,860)$, так и двухстороннего $(2,310)$. Данный факт говорит о том, что присутствующие незначительные различия в приростах между экспериментальными и контрольной пробными площадями в период до проведения рубки являются случайными и средние значения прироста не считаются достоверно отличающимися друг от друга, т. е. значения приростов принадлежат к одной совокупности данных и статистически не различимы.

Следовательно, на основании использования двухвыборочного $t$-критерия Стьюдента можно сделать вывод, что до проведения рубки обновления подрост сосны на всех пробных площадях имеет одинаковый темп роста в высоту [17].

Совершенно иная ситуация наблюдается в период 2014-2020 гг. (после проведения рубки обновления). Здесь значение показателя «t-статистика» $(3,796)$ выше значения $t$ критического как одностороннего $(1,895)$, так и двухстороннего $(2,365)$. Это значит, что различия между значениями приростов на пробных площадях с проведенной рубкой обновления и значениями приростов на контрольной пробной площади не случайные и средние значения приростов достоверно различаются между собой.

Проанализировав данные различия, было определено, что показатели прироста на пробных площадях в среднем на 44,3\% превышают аналогичные показатели на контроле.

Более того, учитывая, что $t$-статистика больше $t$ критического двухстороннего, наблюдаемые различия между средними значениями приростов являются статистически достоверными на уровне значимости $\alpha=0,05$, т. е. на 95\%-ном доверительном уровне [17].

Сравнение между собой средних значений прироста в пределах пробных площадей, пройденных рубками обновления, до и после проведения рубки показало, что в результате проведения первого приема рубки обновления средний годичный линейный прирост подроста сосны обыкновенной увеличился на $33,5 \%$.

На основании вышеизложенного и результатов анализа с применением $t$-критерия Стьюдента можно сделать вывод об эффективности проведения рубок обновления в сосняках мшистых и их влиянии на величину показателя среднего годичного линейного прироста соснового подроста.

Заключение. В результате проведения исследований в сосняках мшистых Нарочанского лесничества ГОЛХУ «Вилейский опытный лесхоз» было установлено следующее:

1) рубки обновления оказывают положительное влияние на формирование и темп роста в высоту подроста сосны обыкновенной;

2) проведение первого приема рубки обновления в сосняке мшистом способствует увеличению среднегодичного линейного прироста подроста сосны обыкновенной предварительной генерации на $33,5 \%$;

3) на 95\%-ном доверительном уровне установлено, что средние значения линейного прироста подроста сосны обыкновенной в насаждениях, пройденных рубками обновления, в среднем на $44,3 \%$ выше, чем в аналогичных по условиям произрастания насаждениях, где рубка обновления не проводилась.

\section{Список литературы}

1. Ангальт Е. М. Анализ прироста соснового подроста и молодняка в сосново-ясеневых культурах // Известия Оренбургского государственного аграрного университета. 2013. № 6 (44). С. 31-34. 
2. Мачык М. Ш. Прирост подроста сосны в высоту в условиях Усинского лесничества // Современные научные исследования и инновации. 2016. № 6 (62). С. 255-258.

3. Кухта А. Е. Линейный и радиальный приросты сосны обыкновенной в Волжско-Камском и Центрально-Лесном государственных природных заповедниках // Вестник Московского государственного университета леса - Лесной вестник. 2010. № 3. С. 88-93.

4. Янбаев Ю. А. Динамика роста подроста сосны обыкновенной на неосваиваемых землях // Известия Оренбургского государственного аграрного университета. 2018. № 4 (72). С. 150-151.

5. Басакова И. Н. Ход роста искусственных насаждений сосны обыкновенной в условиях Бузулукского бора // Известия Оренбургского государственного аграрного университета. 2017. № 2 (64). C. $50-53$.

6. Кожевников А. М. Изменение текущего прироста в ельниках при разной степени их изреживания // Лесное хозяйство. 1973. № 2. С. 34-38.

7. Луганский Н. А. Лесоведение: учебник. Екатеринбург: УГЛТУ, 2010. 432 с.

8. Тагиров В. В. Изменчивость годичного прироста в высоту подроста сосны обыкновенной в разных лесорастительных условиях // Вестник Башкирского государственного аграрного университета. 2018. № 2. C. 139-143.

9. Мачык М. Ш. Ход роста молодых деревцев сосны обыкновенной (Pinus sylvestris L.) // Хвойные бореальной зоны. 2018. Т. 36, № 4. С. 316-321.

10. Романовская А. А. Изменчивость линейного прироста посадок и естественного возобновления сосны обыкновенной на территории Пензенской области // Труды Санкт-Петербургского научно-исследовательского института лесного хозяйства. 2017. № 1. С. 4-13.

11. Борко А. Ч. Влияние минерализации почвы на текущий прирост соснового подроста по высоте после проведения полосно-постепенных рубок // Труды БГТУ. № 1: Лесное хозяйство. 2013. С. 61-63.

12. Тагиров В. В. О средовой и генетической составляющих различий прироста в высоту у сосны обыкновенной на заброшенных сельскохозяйственных землях // Вестник Башкирского университета. 2015. T. 20, № 3. С. $889-891$.

13. Тагиров В. В. Об индивидуальной изменчивости прироста в высоту у подроста сосны обыкновенной на заброшенных сельскохозяйственных землях // Вестник Оренбургского государственного университета. 2015. № 10 (185). С. 97-99.

14. Парамонов Е. Г. Интенсивность роста подроста сосны в пригородных лесах // Вестник Алтайского государственного аграрного университета. 2012. № 9 (95). С. 46-48.

15. Лековская М. В. Влияние рубок ухода на текущий прирост в высоту сосняков мшистых Барановичского лесхоза // Актуальные проблемы лесного комплекса. 2014. № 39. С. 69-72.

16. Макарова Н. В. Статистика в Excel: учеб. пособие. М.: Финансы и статистика, 2002. 368 с.

17. Борздова Т. В. Основы статистического анализа и обработка данных с применением Microsoft Excel: учеб. пособие. Минск: ГИУСТ БГУ, 2011. 75 с.

\section{References}

1. Angal't E. M. Analysis of the increment of pine undergrowth and young growth in pine-ash crops. Izvestiya Orenburgskogo gosudarstvennogo agrarnogo universiteta [Bulletin of the Orenburg State Agrarian University], 2013, no. 6 (44), pp. 31-34 (In Russian).

2. Machyk M. Sh. Growth of pine undergrowth in height in the conditions of Usinsky forestry. Sovremennyye nauchnyye issledovaniya $i$ innovatsii [State-of-the-art research and innovation], 2016, no. 6 (62), pp. 255258 (In Russian).

3. Kukhta A. E. Linear and radial increments of pine in the Volzhsko-Kamsky and Central Forest State Natural Reserves. Vestnik Moskovskogo gosudarstvennogo universiteta lesa-Lesnoy vestnik [Moscow State Forest University Bulletin - Forest Bulletin], 2010, no. 3, pp. 88-93 (In Russian).

4. Yanbaev $\mathrm{Yu}$. A. Growth dynamics of pine undergrowth on uncultivated lands. Izvestiya Orenburgskogo gosudarstvennogo agrarnogo universiteta [Bulletin of the Orenburg State Agrarian University], 2018, no. 4 (72), pp. 150-151 (In Russian).

5. Basakova I. N. Growth course of artificial plantations of pine in the conditions of the Buzuluk pine forest. Izvestiya Orenburgskogo gosudarstvennogo agrarnogo universiteta [Bulletin of the Orenburg State Agrarian University], 2017, no. 2 (64), pp. 50-53 (In Russian).

6. Kozhevnikov A. M. Changes in the current growth in spruce forests at different degrees of thinning. Lesnoye khozyaystvo [Forestry], 1973, no. 2, pp. 34-38 (In Russian). 
7. Luganskiy N. A. Lesovedeniye: uchebnik [Forestry: textbook]. Ekaterinburg, UGLTU Publ., $2010,432 \mathrm{p}$.

8. Tagirov V. V. Variability of annual growth in height of pine undergrowth in different forest growing conditions. Vestnik Bashkirskogo gosudarstvennogo agrarnogo universiteta [Bulletin of the Bashkir State Agrarian University], 2018, no. 2, pp. 139-143 (In Russian).

9. Machyk M. Sh. Growth progress of young pine trees (Pinus sylvestris L.). Khvoynyye boreal'noy zony [Boreal conifers], 2018, vol. 36, no. 4, pp. 316-321 (In Russian).

10. Romanovskaya A. A. Variability of linear growth of plantings and natural regeneration of pine in the Penza region. Trudy Sankt-Peterburgskogo nauchno-issledovatel'skogo instituta lesnogo khozyaystva [Proceedings of the St. Petersburg Scientific Research Institute of Forestry], 2017, no. 1, pp. 4-13 (In Russian).

11. Borko A. Ch. Influence of soil mineralization on the current increment of pine undergrowth in height after strip-gradual felling. Trudy BGTU [Proceedings of BSTU], no. 1: Forestry, 2013, pp. 61-63 (In Russian).

12. Tagirov V. V. On the environmental and genetic components of the differences in height gain in pine on abandoned agricultural lands. Vestnik Bashkirskogo universiteta [Bulletin of the Bashkir University], 2015, vol. 20, no. 3, pp. 889-891 (In Russian).

13. Tagirov V. V. On the individual variability of the increase in height in Scots pine undergrowth on abandoned agricultural lands. Vestnik Orenburgskogo gosudarstvennogo universiteta [Bulletin of the Orenburg State University], 2015, no. 10 (185), pp. 97-99 (In Russian).

14. Paramonov E. G. Growth rate of pine undergrowth in suburban forests. Vestnik Altayskogo gosudarstvennogo agrarnogo universiteta [Altai State Agrarian University Bulletin], 2012, no. 9 (95), pp. 46-48 (In Russian).

15. Lekovskaya M. V. Effect of thinning on the current growth in height of pinetum pleuroziosum forests in Baranovichi forestry. Aktual'nyye problemy lesnogo kompleksa [Actual problems of the forestry complex], 2014, no. 39, pp. 69-72 (In Russian).

16. Makarova N. V. Statistika v Excel: uchebnoye posobiye [Statistics in Excel: a tutorial]. Moscow, Finansy i statistika Publ., 2002. 368 p.

17. Borzdova T. V. Osnovy statisticheskogo analiza i obrabotka dannykh s primeneniyem Microsoft Excel: uchebnoye posobiye [Basics of statistical analysis and data processing using Microsoft Excel: a tutorial]. Minsk, GIUST BGU Publ., 2011. 75 p.

\section{Информация об авторе}

Прищепов Алексей Александрович - магистр сельскохозяйственных наук, аспирант кафедры лесоводства. Белорусский государственный технологический университет (220006, г. Минск, ул. Свердлова, 13a, Республика Беларусь). E-mail: alexey-fox94@mail.ru

\section{Information about the author}

Prishchepov Aleksey Aleksandrovich - Master of Agriculture, $\mathrm{PhD}$ student, the Department of Silviculture. Belarusian State Technological University (13a, Sverdlova str., 220006, Minsk, Republic of Belarus). E-mail: alexey-fox94@mail.ru 